\title{
Topics IN NeUROLOGY
}

\section{Osteochondroma and Spinal Cord Compression in a Patient With Hereditary Multiple Exostoses: A Case Report}

\author{
Robert J. Zoboski, DC
}

\begin{abstract}
Objective: The purpose of this report was to describe the presentation of a patient with hereditary multiple exostoses and thoracic spinal cord compression from an osteochondroma.

Clinical Features: A 31-year-old female presented to a chiropractic clinic with a history of hereditary multiple exostoses and back pain that had existed since the age of 16 years. She had a past medical history that was remarkable for 3 prior surgeries for mass removal. Examination revealed a left upper midscapular mass with decreased sensation.

Intervention/Outcome: Magnetic resonance imaging, computed tomography, and biopsy led to a diagnosis of osteochondroma. These diagnostic modalities confirmed that there was no malignant degeneration. Initial magnetic resonance imaging revealed a large expansive lesion involving the left posterior elements at the region of T3-T4. Subsequent thoracic hemilaminectomy and resection of the spinal tumor with posterior instrumentation and stabilization from T2-T5 resulted in $90 \%$ overall subjective improvement.

Conclusions: A detailed case history, thorough examination, guided advanced imaging, and biopsy provide important information for the diagnosis and appropriate treatment of expansive lesions in patients with hereditary multiple exostoses. (J Chiropr Med 2017;16:72-77)

Key Indexing Terms: Exostoses, Multiple Hereditary; Bone Neoplasms; Spinal Cord Compression; Chiropractic; Osteochondroma
\end{abstract}

\section{INTRODUCTION}

Many osteochondromas are asymptomatic; however, complications can involve bone, nerve, and soft tissues via mass effect or intrinsic change ${ }^{1-10}$ (Fig 1).

Osteochondromas (osteocartilagenous exostoses) represent most of the primary benign bone tumors. ${ }^{7,11-13}$ Osteochondromas are common in the appendicular skeleton. Sixty-five percent of these tumors are located around the knee and proximal humerus and $20 \%$ arise in the axial skeleton, and of these, approximately $5 \%$ occur in the vertebral column. ${ }^{1,14-16}$ Solitary osteochondromas develop in isolated bones and are not hereditary, whereas multiple osteochondromas can occur spontaneously or as part of an autosomal dominant disorder known as hereditary multiple exostosis (HME). ${ }^{10}$ Both genders can be affected equally, but there is a slight male predominance. ${ }^{17,18}$ The incidence of HME is approximately 1 in 50000 live births. ${ }^{3,13,19,20}$

Private Practice, Summit, IL.

Corresponding author: Robert Zoboski, DC, 7355 West Archer Ave, Ste. C, Summit, IL 60501. Tel.: +1 7084587700.

(e-mail: r.zoboski@comcast.net).

Paper submitted January 28, 2015; in revised form August 31, 2016; accepted October 12, 2016.

1556-3707

(C) 2016 National University of Health Sciences.

http://dx.doi.org/10.1016/j.jcm.2016.10.007
This case describes the presentation, management, and outcome for a patient with a past history of HME presenting with back pain as the result of thoracic spine osteochondroma.

\section{Case Report}

A 31-year-old white woman with known HME presented with thoracic pain that had worsened over the past few years. Phenotypical appearance was consistent with HME. Pain had been present since the age of 16 years. Spinal imaging (spiral computed tomography [CT]) had been performed 6 years earlier, but no clinical treatment had been provided (Fig 2). Pain was the chief complaint, with a secondary tingling sensation in the left upper midscapular region. Past medical history was remarkable for previous surgical intervention for mass removal: right ankle at the ages of 8 and 16 years and the left ankle, fibula, and right wrist at the age of 21 years. The patient was also being treated for fibromyalgia and bipolar disorder. Her current medications included carbamazepine (Tegretol).

Examination revealed a large, non-edematous, immobile, and tender left upper midscapular mass at T2-T6. There were decreased pinprick and light touch sensations in the T6 dermatome distribution on the left side. The patient also had hard, nonmobile, and nontender masses in the proximal 


\begin{tabular}{|c|c|c|c|}
\hline Soft Tissue & Vascular & Neurologic & Bone/Joint \\
\hline $\begin{array}{l}\text { Impingement } \\
\text { (muscle, tendon) }\end{array}$ & $\begin{array}{l}\text { Arteriovenous } \\
\text { compression } \\
\text { Superficial } \\
\text { Femoral, popliteal } \\
\text { artery. Common } \\
\text { carotid, vertebral, } \\
\text { subclavian artery. }\end{array}$ & $\begin{array}{l}\text { Neuropathy, } \\
\text { (common } \\
\text { peroneal/(lateral } \\
\text { popliteal nerve) }\end{array}$ & $\begin{array}{l}\text { Deformity: bowing of long } \\
\text { bones/forearms(radius), } \\
\text { short stature, leg length } \\
\text { discrepancy, varus deformity } \\
\text { (femur), valgus deformity } \\
\text { (tibia) }\end{array}$ \\
\hline $\begin{array}{l}\text { Friction, Bursae } \\
\text { Formation(scapula, } \\
\text { hip, shoulder) }\end{array}$ & $\begin{array}{l}\text { Pseudoaneurysm } \\
\text { (most common), } \\
\text { (superficial } \\
\text { femoral artery, } \\
\text { popliteal artery) }\end{array}$ & Radiculopathy & Pseudoarthrosis \\
\hline Tenosynovitis & $\begin{array}{l}\text { Arterial } \\
\text { thrombosis }\end{array}$ & Myelopathy & Synostosis \\
\hline Tendon rupture & $\begin{array}{l}\text { Venous } \\
\text { thrombosis }\end{array}$ & $\begin{array}{l}\text { Cord } \\
\text { compression }\end{array}$ & $\begin{array}{l}\text { Articular subluxation (radial } \\
\text { head/radiocapitellar joint) }\end{array}$ \\
\hline \multirow[t]{7}{*}{ Joint restriction } & Thromboembolism & $\begin{array}{l}\text { Cranial Nerve } \\
\text { Deficits }\end{array}$ & Pressure erosion \\
\hline & Arterial rupture & $\begin{array}{l}\text { Cauda Equina } \\
\text { Syndrome }\end{array}$ & Fracture (usually at base) \\
\hline & $\begin{array}{l}\text { Pericardial } \\
\text { effusion }\end{array}$ & Myelomalacia & \\
\hline & $\begin{array}{l}\text { Hemothorax (rib } \\
\text { exostosis) }\end{array}$ & $\begin{array}{l}\text { Thoracic outlet } \\
\text { syndrome }\end{array}$ & \\
\hline & $\begin{array}{l}\text { Aneurysm } \\
\text { (posterior tibial } \\
\text { artery) }\end{array}$ & & \\
\hline & Hemopericardium & & \\
\hline & Pneumothorax & & \\
\hline
\end{tabular}

Fig I. Complications of osteochondroma. Reported soft tissue, vascular, neurologic, and bone/joint complications.

aspect of the tibia in both legs. The second toe of her left foot was observed to be short. The remainder of the neurologic examination was essentially normal, with the exception of depressed patellar and Achilles reflexes. There was no evidence of myelopathy.

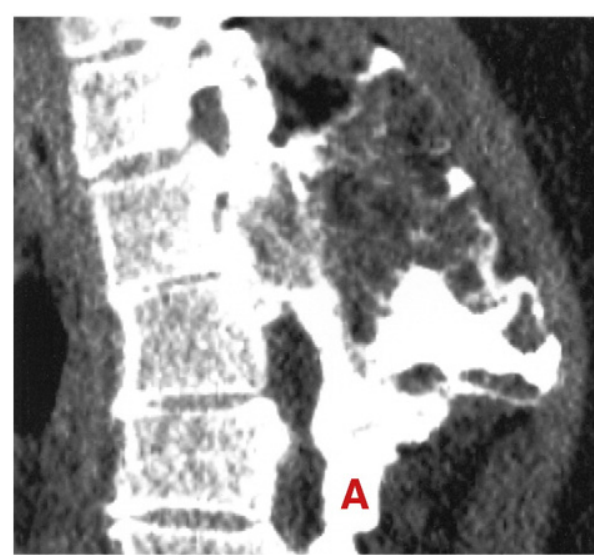

Noncontrast magnetic resonance imaging (MRI) of the thoracic spine revealed a large lesion involving the left posterior elements of T3-T5 (Fig 3). The mass extended inferiorly involving the left posterior elements at the T4 and T5 levels. There was associated mild to moderate stenosis

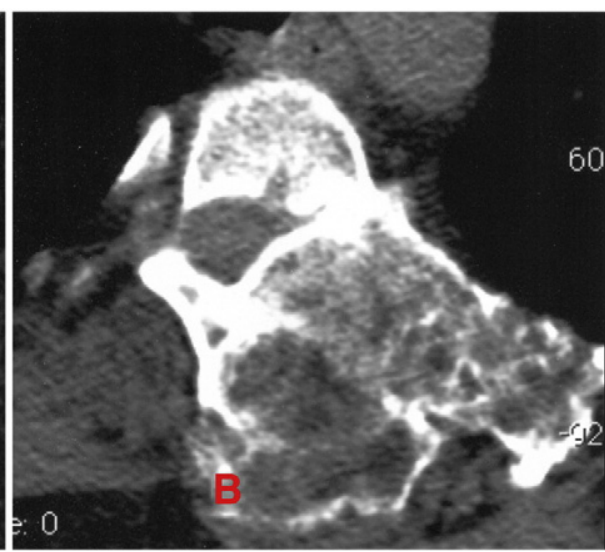

Fig 2. Spiral computed tomography showing left-sided, broad-based, sessile bony mass with spinal canal and lateral recess stenosis (6 years prior). Sagittal (A) and axial (B) views. 

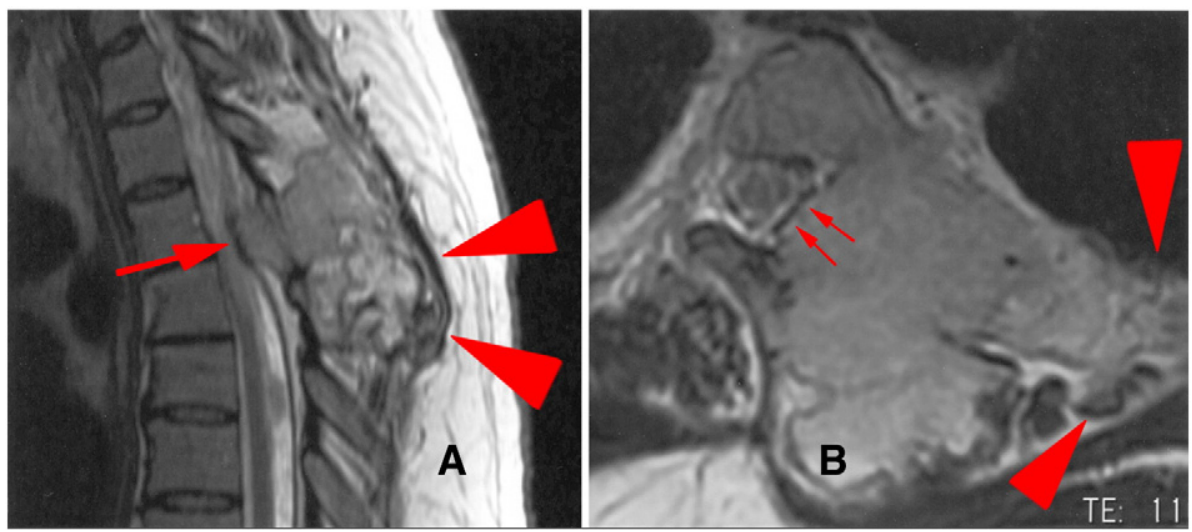

Fig 3. T2-weighted magnetic resonance imaging sequence showing sessile morphology (arrowheads) and mass effect on spinal cord and intervertebral foramina at T3-T4 (arrows). Sagittal (A) and axial (B) views.

of the spinal canal and left intervertebral foramen. Contrast-enhanced CT demonstrated a mass involving the left posterior elements of T3 but did not show any significant serial change from CT studies performed 6 years ago. There was no significant soft tissue component. CT-guided biopsy was negative for malignant cells, and no cartilaginous component was identified. Microscopic features revealed osteochondroma with normal cellular bone marrow with few lymphoid aggregates.

The patient subsequently underwent a thoracic hemilaminectomy and resection of the spinal tumor with posterior instrumentation and stabilization of T2-T5. Postoperative pain required the use of opioids, which were continued for approximately 3 months after the surgery. The patient subsequently underwent 6 months of physical therapy, which resulted in an overall subjective improvement of $90 \%$.

Postoperative thoracic pain returned after 2 years, prompting further imaging to rule out an enlarging cartilaginous cap. Repeat CT and MRI were unremarkable for any recurrent enhancing tumor (Fig 4). The patient responded favorably to a brief course of physical therapy and was discharged from active care.

\section{DISCUSSION}

This case illustrates a case of a 31-year-old woman with back pain secondary to a large osteochondroma in the upper thoracic spine. Spinal involvement of osteochondromas is rare and most often occur in the posterior elements of the cervical (50\%) and upper thoracic vertebra: T8 and T4, respectively. ${ }^{11,21}$ Although the exact mechanism behind osteochondromas is not fully understood, spinal involvement typically occurs in the neural arch where the secondary ossification centers reside. ${ }^{22}$ Spinal lesions can lead to neurologic compromise, including medullary compression and encroachment on peripheral nerves. ${ }^{13}$

In this case, the patient showed no neurologic deficit other than unilateral decreased sensation in the left upper thoracic dermatomes at T2-T6. There was no evidence of myelopathy in spite of a rather large-sized tumor causing cord compression. This sessile mass led to encroachment of the posterior lateral aspect of the spinal canal and foramen at the levels of T3 and T4. Musculoskeletal differential considerations included thoracic radiculopathy and intercostal neuralgia. Pain, not aesthetics, was the primary reason for this patient's initial presentation to our clinic. The paucity of neurologic findings may explain the patient's delay in seeking follow-up care.

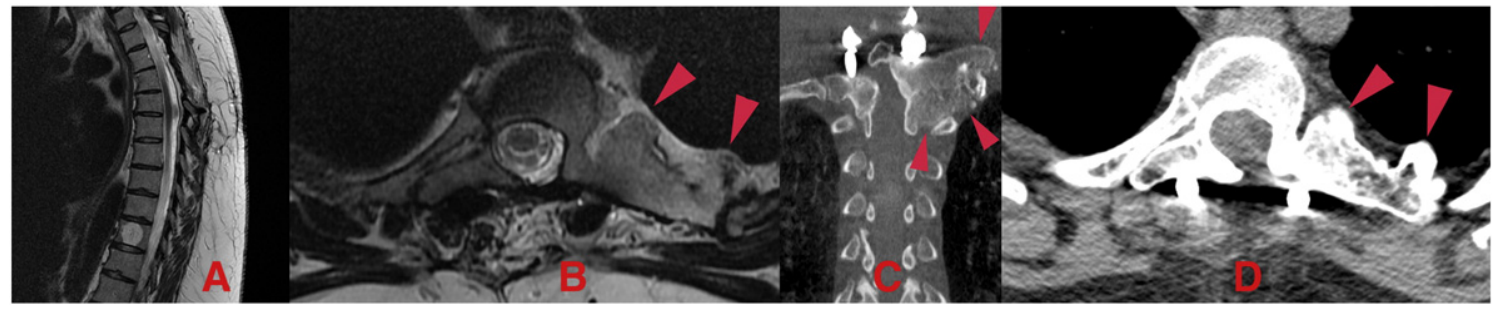

Fig 4. T2-weighted magnetic resonance imaging sagittal (A) and axial (B) views and computed tomography coronal (C) and axial (D) views, 2 years following surgery. Note that there is no enlargement of cartilaginous cap (arrowheads). 
The patient's past family history and personal medical history supported phenotypical expression of HME. Since osteochondromas are typically benign and reach maturity in childhood, progressive pain in an adult with HME is worrisome. $3,5,7,23$ Examination findings of a large, tender, nonmobile thoracic mass necessitate further evaluation to rule out an enlarging cartilaginous cap and malignant transformation. ${ }^{13,24,25}$

Single osteochondroma has been described as a benign neoplasm, whereas hereditary multiple osteochondromas have been described as hereditary neoplastic syndrome. ${ }^{18,24}$ However, exostoses are generally considered developmental lesions, secondary to separation of part of the epiphyseal growth plate cartilage that migrates through the periosteum surrounding the growth plate. ${ }^{5,22,26,27}$ Hereditary multiple exostoses has also been called diaphyseal aclasis, multiple hereditary exostoses, and multiple osteochondromatoses. ${ }^{12,18,28,29}$

Mutations of the genes exostosin-1 (EXT1) (8q23-q24) and exostosin-2 (EXT2) (11p11-p12) have associations with HME and malignant degeneration. ${ }^{4,5,26,28,30}$ The EXT genes regulate chondrocyte maturation and differentiation. ${ }^{31}$

The majority of osteochondromas are found in long bones and the appendicular skeleton; however, they can be found in any bone formed through endochondral ossification. 11,18,24 Small lesions may remain asymptomatic.

Many complications can occur from solitary and multiple osteochondromas. In this case, the patient exhibited slight bowing of the right lower extremity and range-of-motion limitations with forearm supination secondary to mass effect. Conservative management can be challenging and requires skilled and accurate vascular, neurologic, and biomechanical evaluation of the spine and extremities. Complications are found more often in patients with multiple lesions than in those with a solitary osteochondroma. ${ }^{2,3}$ Solitary osteochondromas are found in the spine $1 \%$ to $4 \%$ of the time, whereas spinal occurrence is seen in $7 \%$ to $9 \%$ of patients with HME. ${ }^{9}$ Patients with vertebral osteochondromas associated with HME present with spinal cord compression $96 \%$ of the time. ${ }^{21}$

When considering the differential diagnosis, age is one of the most important factors. Diagnostic possibilities in a child are different from those in an adult. Lesions almost exclusively seen in children or young adults are nonossified fibroma, unicameral bone cyst, aneurysmal bone cyst, osteosarcoma, or Ewing sarcoma. ${ }^{13}$ In patients over 40 years of age, multiple myeloma and metastatic lesions are the most common malignant bone tumors. ${ }^{13}$ Differential considerations for HME include solitary osteochondroma, multiple enchondromatosis, osteoblastoma, aneurysmal bone cyst, and chondrosarcoma. 11,18,32

Although there is no consensus with regard to the definition of the critical path to diagnosis, it is generally agreed that a skeletal survey should be performed once the affected individual reaches skeletal maturity. The survey is used for subsequent comparison should concerns arise. $^{6,23,24}$ Plain film radiography is followed by nuclear imaging. ${ }^{23}$ If there are worrisome features, ultrasonography, with or without contrast-enhanced CT and MRI, is useful for obtaining fine anatomical details, preoperative planning, and elucidation of the cartilaginous cap. ${ }^{24,25}$

After making the diagnosis of osteochondroma, characteristics that distinguish benign lesions from malignant lesions must be sought. The path toward the final diagnosis is heavily dependent on advanced imaging and biopsy examinations; the latter may be avoided by using ultrasonography or contrast-enhanced MRI, depending on the location and morphology of the osteochondroma. ${ }^{33}$ Malignant transformation to chondrosarcoma occurs in approximately $1 \%$ of solitary lesions, and the incidence ranges from $0.5 \%$ to $5 \%$ for enlarging osteochondromas in those with HME. ${ }^{14,25,34,35}$ There is no reliable imaging method to distinguish between a low-grade chondrosarcoma and a benign cartilaginous tumor. ${ }^{3}$

Because of the complexity of the thoracic lesion in this case, CT, MRI, and CT-guided biopsy were the diagnostic tests of choice.

Malignant transformation is almost invariably caused by chondrosarcoma arising in the cartilage cap of the lesion. ${ }^{14,35}$ The size of the cartilaginous cap is used to determine the likelihood of malignant transformation. Size can be established with ultrasonography (if the lesion is superficial) or contrast-enhanced CT and MRI to differentiate bursa formation from the actual cartilaginous cap. Cartilaginous caps greater than $1 \mathrm{~cm}$ should be considered suspicious. ${ }^{3,23,28}$

In the present case, repeat CT and MRI were performed 2 years after the initial surgery because of the return of thoracic symptoms. There was no enhancing tumor (growing cartilaginous cap) at the site of repair. The symptoms were more likely related to thoracic neuromuscular perturbation, since the patient responded appropriately to a brief course of physical therapy.

Treatment of the spinal lesion in this case involved thoracic decompression and removal of the tumor followed by 5 -level stabilization. Surgical excision with fusion resulted in a $90 \%$ reduction of pain. Surgery is the treatment of choice when there are neurologic complications other than pain. ${ }^{2,28}$

Although the midscapular mass was palpable in this patient, lesions may be obscured by obesity or may reside in regions of the skeleton that are difficult to palpate. Because adolescent and adult obesity has increased rapidly in the United States and most osteochondromas are diagnosed by the age of 12 years, lesions in adults may go unnoticed. This raises 2 important points: First, adolescents with a positive family history of HME may benefit from instruction on body awareness and self-education as a method of following disease progression. Second, musculoskeletal specialists, including chiropractic physicians, may play a role in defining a more proactive strategy to educate affected individuals and monitoring them on a serial basis. At least in theory, this may lead to earlier intervention and 
overall decreased morbidity, particularly in the case of compressive spinal lesions. ${ }^{36}$

\section{Limitations}

This is a single retrospective description of a patient presentation. The findings of this case may not necessarily represent other patients with similar diagnoses.

\section{CONCLUSIONS}

Although this case depicted a rare spinal lesion, clinicians should recognize the symptoms associated with malignant transformation of a benign osseous tumor. Osteochondromas can affect neurovascular and other soft tissues as well as bone and joint function. This makes serial orthopedic and neurologic evaluations important for treatment planning and surgical decision making.

\section{Practical Applications}

- Osteochondromas may lead to soft tissue, bone, and joint complications that require serial neurologic, orthopedic, and vascular re-evaluation for appropriate management.

- Suspicious spinal osteochondromas require advanced imaging.

- Clinicians should recognize that benign tumors can become malignant.

\section{ACKNOWLEDGMENTS}

The author would like to thank Russell Iwami, MSLS, reference librarian at the National University of Health Sciences, for his help in retrieving some key articles for this case report.

\section{Funding SOURCES AND CONFlictS OF INTEREST}

No funding sources or conflicts of interest were reported for this study.

\section{CONTRIBUTORSHIP INFORMATION}

Concept development (provided idea for the research): R.J.Z.
Design (planned the methods to generate the results): R.J.Z.

Supervision (provided oversight, responsible for organization and implementation, writing of the manuscript): R.J.Z.

Data collection/processing (responsible for experiments, patient management, organization, or reporting data): R.J.Z.

Analysis/interpretation (responsible for statistical analysis, evaluation, and presentation of the results): R.J.Z.

Literature search (performed the literature search): R.J.Z.

Writing (responsible for writing a substantive part of the manuscript): R.J.Z.

Critical review (revised manuscript for intellectual content, this does not relate to spelling and grammar checking): R.J.Z.

\section{REFERENCES}

1. Han I, Kuh S. Cervical osteochondroma presenting as Brown Sequard syndrome in a child with hereditary multiple exostosis. $J$ Korean Neurosurg Soc. 2009;45(5):309-311.

2. Bottner F, Rodl R, Kordish I, Winkelmann W, Gosheger G, Linder N. Surgical treatment of symptomatic osteochondroma. $J$ Bone Joint Surg Br. 2003;85(8):1161-1165.

3. Kivioja A, Ervasti H, Kinnunen J, Kaitila I, Wolf M, Bohling T. Chondrosarcoma in a family with multiple hereditary exostoses. J Bone Joint Surg Br. 2000;82(2):261-266.

4. Porter DE, Lonie L, Fraser M, et al. Severity of disease and risk of malignant change in hereditary multiple exostoses. $J$ Bone Joint Surg Br. 2004;86(7):1041-1046.

5. Liu W, Kong D, Tang J, Yu F. Giant costal osteochondroma in a man with multiple exostoses. Ann Thorac Surg. 2013;96(2): 675-677.

6. Cowles RA, Rowe DH, Arkovitz MA. Hereditary multiple exostosis of the ribs: an unusual cause of hemothorax and pericardial effusion. J Pediatr Surg Case Rep. 2005;40(7): 1197-1200.

7. Niedzwiecka M, Kaczmarek P, Krawczyk T, Oszukowski P, Maroszynska I. Benign but fatal. A case of a new born with congenital osteochondroma. Bone. 2013;54(1):169-171.

8. Khurana JS, McCarthy EF. Benign cartilage tumors. Diagn Histopathol (Oxford). 2014;20(5):190-199.

9. Blitz NM, Lopez KT. Giant solitary osteochondroma of the inferior medial calcaneal tubercle: a case report and review of the literature. J Foot Ankle Surg. 2008;47(3):206-212.

10. Reckelhoff KE, Green MN, Kettner NW. cervical spine osteochondroma: rare presentation of a common lesion. J Manip Physiol Ther. 2010;33(9):711-715.

11. Choi BK, Han IH, Cho WH, Cha SH. Lumbar osteochondroma arising from spondylolytic L3 lamina. J Korean Neurosurg Soc. 2010;47(4):313-315.

12. Bowen EB, Boyden ED, Holm IA, et al. Loss-of-function mutations in PTPN11 cause metachondromatosis, but not Ollier disease or Maffucci syndrome. PLoS Genet. 2011;7(4): e1002050.

13. Pollock R. Management of benign bone tumors. Orthop Trauma. 2009;23(4):248-257.

14. Miller SL, Hoffer FA. Malignant and benign bone tumors. Am 2001;39(4):673-699.

15. Burki V, So A, Aubry-Rozier B. cervical myelopathy in hereditary multiple exostosis. Joint Bone Spine. 2011;78(4): $412-414$. 
16. Sinelnikov A, Kale H. Osteochondromas of the spine. Clin Radiol. 2014;69(12):e584-e590.

17. De Andrea CE, Hogendoom PC. Molecular genetics of chondroid tumors. Diagn Histopathol (Oxford). 2014;20(5): 165-171.

18. Bovee JVMG. Multiple osteochondromas. Rare Dis. 2008;3(3): 1-7.

19. Clement ND, Ng CE, Porter DE. Shoulder exostoses in hereditary multiple exostoses: probability of surgery and malignant change. J Shoulder Elb Surg. 2011;20(2):290-294.

20. McCarthy CM, Blecher H, Reich S. A case of myelopathy because of enchondromas from Marfucci syndrome with successful surgical treatment. Spine J. 2015;15(6):e15-e19.

21. Philippe C, Porter DE, Emerton ME, et al. Mutation screening of EXT1 and EXT2 genes in patients with hereditary multiple exostoses. Hum Genet. 1997;61(3):520-528.

22. Hakim DN, Pelly T, Kulendran M, Caris JA. Benign tumors of the bone: a review. J Bone Oncol. 2015;4(2):37-41.

23. Pauli RM. The natural histories of bone dysplasias in adults - vignettes, fables and just so stories. Semin Med Genet. 2007;145C(3):309-321.

24. Lee KCY, Davies AM, Cassar-Pullicino VN. Imaging the complications of osteochondromas. Clin Radiol. 2002;57(1): 18-28.

25. Kyriazoglou AI, Dimitriadis E, Arnogiannaki N, Brandal P, Heim S, Pandis N. Similar cytogenetic findings in two synchronous secondary peripheral chondrosarcomas in a patient with multiple osteochondromas. Cancer Genet. 2011;204(12): 677-681.

26. Gottschalk HP, Kanauchi Y, Bednar MS, Light TR. Effective of osteochondroma location on forearm deformity in patients with multiple hereditary osteochondromatosis. J Hand Surg Am. 2012; 37(11):2286-2293.

27. Danner-Koptik K, Kletezel M, Dilley KJ. Exostosis as a long-term sequela after pediatric hematopoietic progenitor cell transplantation: potential causes and increase risk of secondary malignancies from an and Robert H Lurie Children's Hospital of Chicago. Biol Blood Marrow Transplant. 2013; 19(8):1267-1270.

28. Ham SJ. Multiple hereditary exostoses. Clinical problems and therapeutic options. Orthop Trauma. 2013;27(2):118-125.

29. Perl M, Brenner RE, Lippacher S, Nelitz M. Dysplasia epiphysealis hemimelica: a case report with novel pathophysiologic aspects. Clin Orthop Relat Res. 2009;467(9):2472-2478.

30. Narvid J, Gorno-Tempini ML, Slavotinek A, et al. Of the brain and bone: the unusual case of Dr. A. Neurocase. 2009;15(3): 190-205.

31. Balach T, Stacy GS, Peabody TD. The clinical evaluation of bone tumors. Am. 2011;49(6):1079-1093.

32. Mesfin A, Ghermandi R, Castiello E, Donati DM, Boriani S. Secondary chondrosarcoma of the lumbar spine in hereditary multiple exostoses. Spine J. 2013;13(9):1158-1159.

33. Costa FM, Canella C, Gasparetto E. Advanced magnetic resonance imaging techniques in the evaluation of musculoskeletal tumors. Am. 2011;49(6):1325-1358.

34. Motameti K, Seeger LL. Benign bone tumors. Am. 2011;49(6): 1115-1134.

35. Pannier S, Legeai-Mallet L. Hereditary multiple exostoses and enchondromatosis. Best Pract Res Clin Rheumatol. 2008;22(1): 45-51.

36. Mataliotakis G, Tsirikos A. Bone tumors affecting the spine in children and adolescents. Orthop Trauma. 2011;25(4):300-310. 